\title{
Study of the Bottleneck Faced by the Theme-based Flipped Teaching Model and its Countermeasures
}

\author{
Gao Jian-jun, Zhang Tong-guang, Zhang Li-nan \\ Heilongjiang University of Technology, Jixi
}

Keywords: theme-based, flipped teaching model, bottleneck, countermeasures

\begin{abstract}
As an emerging education concept and teaching form, the theme-based flipped teaching model has optimized the teaching structure of traditional classroom and realized the subversion of the current traditional teaching model, which has not only provided individualized teaching model for teachers' teaching, but also opened up new ideas of teaching reform for teachers. Furthermore it has provided individualized and in-depth learning inquisition and thinking space for students and stimulated students' enthusiasm for active learning, which is conducive to cultivating students' innovative thinking and critical thinking. Based on that, this paper has analyzed the bottleneck faced by the model of flipped teaching after exploring the Theme-based Flipped Teaching Model and its teaching practice significance, and then put forward the development countermeasures for Theme-based Flipped Teaching Model.
\end{abstract}

Ten-year Development Plan of Educational Informatization(2011-2020) points that, 'the development of educational informatization should take the education's concept innovation as the guide, take the high-quality education resources and the information-based learning environment as the basis and take the learning style and educational model innovation as the core', from which, we can know the high attention that China has paid to education innovation. The flipped teaching, based on information-based educational technology, exactly conforms to the requirements of education planning, besides, as one emerging education concept and teaching form, while it provides the personalized teaching mode for teachers, it provides students with the personalized and in-depth learning inquisition and thinking space.

\section{Theme-based Flipped Teaching Model and Its Teaching Practice Significance}

Theme-based Flipped Teaching Model is to design and divide the professional knowledge or course knowledge according to the thematic content and the content of knowledge will not be organized and presented in its own knowledge system and structure in the domain of traditional and single course knowledge, but divided into thematic units according to the knowledge system, furthermore, a number of theme-based projects and tasks will form within the thematic units. Teachers take a series of thematic units as the main line and the theme-based tasks and projects as the carriers in the process of flipped teaching, besides, the design of teaching activities and the organization of teaching resources are developed always surrounding the theme and in the study course, in the learning process, students take the independent learning, in-class collaborative interaction and mastering as well as the internalization of knowledge according to the provided targeted thematic projects.

The Ministry of Education has clearly put forward in the Ten-year Development Plan of Educational Informatization(2011-2020) that the development task of cultivating students' learning ability in the environment of informatization, promoting the integration of information technology and education depth and innovating the model of talents cultivation. The former refers to improving students' ability of raising questions, analyzing problems and solving problems in the network environment. The latter refers to speeding up the digital transformation of course and specialties, innovating information-based teaching and learning pattern, enhancing the personalized interactive teaching level, innovating talents training model and improving the quality of talents cultivation. 
Therefore, it is of great practical significance to carry on the exploration and research of theme-based flipped teaching in the process of teaching practice. Self-directed learning ability is not only the important education goal for educators, but also the important condition and way for students to acquire knowledge and develop skills. The advantage of theme-based flipped teaching model lies in that, through setting thematic projects for students, it can encourage students to discover and explore problems requiring cognition purposefully, reconstruct the information they obtained to form the divergent thinking knowledge, and then promote students to explore actively the tasks or problems needing to be solved in many ways and perspectives, to think positively with knowledge boundaries, to internalize knowledge, and thus to enhance cognition and thinking. Meanwhile, there are more time and deeper substantive issues in the class for students to discuss with teachers and other students, besides, in the process of problem study, thinking, discussing and solving, turn the knowledge learning into the meaningful and constructive activity filled with inner driving forces. In the process of knowledge thinking, problem exploration and turning the theme-based knowledge into personal knowledge, the theme-based flipped teaching constructs its own understanding framework of knowledge and reconstructs the knowledge system and then the students not only learn the knowledge, but also learn to learn, thus, they can improve their lifelong learning ability and development ability.

\section{Bottleneck Faced by Theme-based Flipped Teaching Model}

Theme-based task design takes the professional teaching content as the fundamental and divides the teaching content into several thematic modules, besides, it develops with real task or projects around the theme and its topics, apart from these, it covers a variety of learning activities, which can promote students' multiple intelligence development, meanwhile, it is also the integral course, which is a supplement to the one-subject course, besides, it disrupts the content and order of the total teaching materials and carries out the reform of the traditional class. However, for the designer of the subject unit, it is difficult to carry out the theme-based task design, because the teachers must have a general cognition, understanding and master of the professional connotation and course knowledge, meanwhile, they also should have a deep study of the professional trend, only after the comprehensive research and thoughtful thinking, can they design the suitable theme-based task.

Concept decides behavior. In the traditional education environment, many teachers have already developed a whole set of professional skills and formed a fixed teaching paradigm and habit. To achieve the flipped classroom, it is necessary to break the balance between ourselves and the education environment, so that to place yourselves in a new and uncertain state, which brings a great challenge to the teacher's education concept and teaching skills, and the teachers need great courage to carry out the reversal concept, theory deepening and reform innovation. Teachers usually do not want to 'renew' their 'life' if they do not have firm reform faith as the support.

For the theme-based flipped teaching, teachers' professional competence and information literacy are the key factors to the success of teaching. The making of education related videos, design of theme related activities, organization and implementation of teaching and the process management are the challenges for teachers' professional ability and technical ability while carrying out the theme-based flipped teaching. In order to meet the needs of students' independent learning, teachers should design the theme-based task, decompose theme-based task, make relevant thematic study video and build a perfect network learning support system according to the requirement of talents cultivation. At the same time, the teachers should also communicate with students and monitor their learning through various interactive tools, besides, the guidance and control of the discussion and communication in classroom is the double test of teachers' wisdom and skills, furthermore, it also puts forward higher requirement for teachers' professional ability, especially under the situation that students have made a adequate preparation, the students will raise various relevant questions or assumption in the class, therefore, the teacher should make identification and guidance and also answer the questions effectively. That requires that the teachers should not only have the solid professional knowledge and extensive interdisciplinary knowledge, but also have a keen ability of thinking. Of course, some problems can realize the mutual compensation to some 
extent by the research group, however, the deficiency of teachers themselves is still the short board during the implementation process of theme-based flipped teaching.

The flipped teaching also gives teachers a new test while giving more classroom time to teachers and students, if there is no effective guidance and teachers still adopt the single form of the past in class, the students will lose interest gradually. If there is no substantive task activities design, the teachers and students may feel bored or have nothing to do in class, therefore, it requires that the teachers should not only observe the students in class and be good at controlling the classroom atmosphere, but also be more sensitive to realize what the most students are confused, furthermore, show the solution timely so as to make an effective guidance.

The theme-based flipped teaching model shifts the knowledge cognition and deep learning to the outside world, and the lead the collision of ideas in class to a deeper level, which completely upsets the students' traditional learning cognition, besides, most of the topics and related questions are completed by students themselves and the learning task has the features of pertinence and immediacy, apart from that, the students should conscientiously complete the tasks assigned by the teachers after class and try to form their own understanding and confusion initially. If the students lack the ability of self-control, do not follow the instructions of the teachers and do not learn in advance, they will not be able to participate in the practical class. In addition, the students also need to improve their information literacy. Apart from watching video, they also need to conduct network resource retrieval and communicate with teachers and students through online teaching platform, which all requires students owning certain degree of information literacy. It not only has changed the students' study habits, but also put forward higher requirements to the student's ability of self-control, ability of learning persistence as well as thinking ability and frustration tolerance ability faced by difficulties, which needs time to adapt to and it is also another bottleneck that the flipped teaching faces.

In the implementation process of theme-based flipped teaching, it requires students completing the imparting of knowledge through the teaching video before class, and then internalizing the knowledge to a certain extent, in which way, can the discussion and communication in class be carried on through various forms of teaching. That requires the students owning complete set of knowledge system and ability of understanding and mastering, however, in fact, the students' ability in this aspect is defective, as the result, it affects the implementation of the theme-based flipped teaching model to a certain extent.

\section{Study of the Development of Theme-based Flipped Teaching Model and Countermeasures}

The core of theme-based flipped teaching is the design of theme-based task, which requires the designer owning a deep understanding and grasp of professional knowledge and professional cultivating requirements and requires professional team finishing it collaboratively, therefore, it is necessary to integrate the teachers into a professional flipped teaching team and take systematic design and overall evaluation on the flipped content so as to form a systematic theme-based unit and systematic unit task.

Teacher, is the practitioner of flipped teaching reform and the most critical and active factor in the implementation process of teaching, therefore, in order to realize the reform of flipped teaching, it must be taken that changing the education concept and strengthening teachers' teaching innovation consciousness. Therefore, the main orientation of flipped teaching is to implement the innovation of classroom teaching so that to improve students' knowledge, intelligence and spirit quality, free students from the constraint of exam-oriented education and cramming education. It can effectively stimulate students' behavioral transformation and ideological transformation as along as the teachers infect the students in creative spirit, drive students by innovation practice and inspire students with innovative achievements. Therefore, the teacher should change the idea, strengthen their teaching innovation consciousness, establish correct scientific development concept, establish the students related concept and the teaching concept conforming to the trend of the times and the requirement of class reform, fully explore their own creativity, take the initiative to absorb new ideas and transform it into new teaching ideas and teaching behavior, study the materials, study 
the students, inspire students' thinking inspiration and creation sparks and create new teaching idea.

The teacher is not only the initiator of knowledge, but also the promoter for the all-round development of students. The flipped teaching requires the construction of famous teacher project, which focuses on building the project team and information-support team, so that the team members can know the flipped teaching very well. Improve the professional ability of the teachers team through the famous teacher project. Teachers' professional competence is the ability and skill that the teachers obtained for successfully completing one task in the process of education and teaching activities. Teachers' professional competence is the most prominent external manifestation of teachers' comprehensive quality, and also the core factor for evaluating teacher's professionalism. Teacher's professional ability mainly includes ability of teaching design, ability of integral conception, ability of expression, organization and management ability of education and teaching, ability of education and teaching communication, ability of education and teaching flexibility, ability of reflection, ability of education and teaching research, ability of innovation etc.

Flipped teaching requires students to be autonomous and independent to study and explore, which is also the fundamental way to cultivate students' learning consciousness and exploration ability. However, the habit is the way of life that forms gradually after a long period and it has certain degree of viscous property, furthermore, it is difficult to change. The flipped classroom teaching mode requires that the schools and teachers conduct systematic and cascade education and guidance for students and during the study period, take the systematic, planned and normative arrangement to help the students form new learning habits, which is helpful for students cultivating their social adaptability and autonomy and then effectively realize the flipped teaching.

In the process of flipped teaching, the students are required to have a certain degree of knowledge, so that they can generate the inquiry thought and solve the inquiry problem preferably. The purpose of broadening students' knowledge is to cultivate their creativity, and the cultivation of creativity is not only related to the quantity of knowledge, but also related to the unique thinking habit and cognition quality. The acquisition of knowledge derives from external information and internal digestion, and the knowledge boundary determines the breadth of information absorption. The method and ability of internal digestion determine the depth of knowledge transformation. The broadening of the knowledge is expanding the boundary and accepting more information, form which seek for the content fitting in with your interests and specialty. This requires students to take the reading purposefully and specifically so that to learn and discuss the absorption of knowledge about your own discipline and the relevant disciplines.

Virtual learning space, learning environment and physical learning environment building provide students with personalized and collaborative learning space. Before class, students can learn knowledge through online learning platform and then expand the knowledge according to their actual situation so that the real-time discussion and communication can be achieved between students and students as well as between teachers and students through the Internet. In class, the breaking of traditional classroom layout makes it easier for students to communicate with teachers and classmates and the students can complete the construction of knowledge in a relaxed and pleasant classroom environment. The transformation of the learning environment guarantees that the students become the center of learning, besides, the teacher's guidance and promotion role can get better playing.

\section{Acknowledgments}

The content of this paper is the scientific research subject of the $13^{\text {th }}$ five-year plan put by Higher Education Academy of Heilongjiang province, namely the Study Result of Knowledge Internalization and Improving Ways of Theme-based Flipped Teaching Under the Perspective of Cognitive Load(subject code:16G493)

\section{References}

[1] Pan Qinghong, Practice Exploration of the 'Reversal' Teaching Model Based on the 
Theme-based Design, Modern Educational Technology,2013,23(11).

[2] Zhang Jinlei, Analysis of the Key Factors for the Teaching Model of Flipped Classroom, Distance Education in China(Integrated Version), 2013(10).

[3] Zhao Liying, Wu Qinglin, Design of Multimedia Learning Environment Based on the Reversal Effect of Knowledge, China Audiovisual Education, 2012(1) 